\title{
Genistein-mediated inhibition of glycosaminoglycan synthesis as a basis for gene expression-targeted isoflavone therapy for mucopolysaccharidoses
}

\author{
Ewa Piotrowska ${ }^{1,5}$, Joanna Jakóbkiewicz-Banecka ${ }^{2,5}$, Sylwia Barańska ${ }^{1}$, \\ Anna Tylki-Szymańska ${ }^{3}$, Barbara Czartoryska ${ }^{4}$, Alicja Wegrzyn ${ }^{2}$ and Grzegorz Wegrzyn*,1
}

\begin{abstract}
${ }^{1}$ Department of Molecular Biology, University of Gdańsk, Kładki 24, Gdańsk 80-822, Poland; ${ }^{2}$ Laboratory of Molecular Biology (affiliated with the University of Gdanisk), Institute of Biochemistry and Biophysics, Polish Academy of Sciences, Kładki 24, Gdańsk 80-822, Poland; ${ }^{3}$ Department of Metabolic Diseases, The Children's Memorial Health Institute, Al. Dzieci Polskich 20, Warsaw 04-736, Poland; ${ }^{4}$ Department of Genetics, Institute of Psychiatry and Neurology, Sobieskiego 9, Warsaw 01-957, Poland
\end{abstract}

Mucopolysaccharidoses (MPS) are inherited, severe, progressive, metabolic disorders caused by deficiencies in different enzymes involved in degradation of glycosaminoglycans (GAGs). Although enzyme replacement therapy (ERT) has recently been available for MPS type I, and clinical trials have been performed in ERT for MPS II and MPS VI, there is little chance that this kind of treatment may be effective for neurodegenerative forms of MPS (due to inefficient delivery of enzymes to central nervous system through the blood-brain barrier), hence currently there is no effective therapy available for them. Therefore, we aim to develop an alternative therapy for these diseases. We found that genistein $\left(4^{\prime}, 5\right.$, 7-trihydroxyisoflavone or 5,7-dihydroxy-3-(4-hydroxyphenyl)-4H-1-benzopyran-4-one) inhibits synthesis of GAGs considerably in cultures of fibroblasts of MPS patients (types I, II, IIIA and IIIB were tested). Prolonged cultivation of these cells in the presence of genistein resulted in reduction of GAG accumulation and normalization of cells as estimated by biochemical tests and electron microscopic analysis, respectively. As genistein inhibits kinase activity of epidermal growth factor receptor, which is required for full expression of genes coding for enzymes involved in GAG production, we propose to consider a substrate reduction therapy for MPS, which is referred to as 'gene expression-targeted isoflavone therapy'. European Journal of Human Genetics (2006) 14, 846-852. doi:10.1038/sj.ejhg.5201623; published online 3 May 2006

Keywords: mucopolysaccharidoses; glycosaminoglycans; genistein; isoflavones; substrate reduction therapy; gene expression-targeted therapy

\section{Introduction}

Glycosaminoglycans (GAGs, formerly called mucopolysaccharides) are compounds synthesized in most tissues of human body and playing important roles in fundamental

*Correspondence: Professor G Wegrzyn, Department of Molecular Biology, University of Gdańsk, Kładki 24, Gdańsk 80-822, Poland. Tel + 4858346 3014; Fax: + 4858301 0072;

E-mail: wegrzyn@biotech.univ.gda.pl

${ }^{5}$ These authors contributed equally to this work.

Received 19 December 2005; revised 2 March 2006; accepted 3 March 2006; published online 3 May 2006 biological processes, mostly by binding to variety of proteins. ${ }^{1}$ Proper turnover of GAGs is ensured by degradation of their excess in lysosomes, which is mediated by specific acid hydrolases. Deficiency in an activity of one of these enzymes leads to accumulation of GAGs in lysosomes of virtually every cell of the body as well as outside of cells. Affected tissues do not perform properly, which leads to progressive damage throughout the body, including the heart, respiratory system, bones, joints and, in some cases, central nervous system. The diseases caused by accumulation of GAGs are called mucopolysaccharidoses (MPS) ${ }^{2}$ In 
fact, degradation of GAGs (mainly heparan sulphate, dermatan sulphate and keratan sulphate) requires actions of several enzymes, and deficiency in one of them causes particular MPS type, characterized by specific clinical features. MPS are genetic, metabolic diseases inherited in an autosomal recessive manner (except MPS II, which is $\mathrm{X}$-linked). ${ }^{2}$ In most cases the disease is fatal, with expected lifespan between one and two decades on average, however, prediction of its severity and clinical progress is usually difficult, even when biochemical and genetic data are available. $^{3}$

Until recently, no effective treatment was available for any MPS type. Since a few years, enzyme replacement therapy (ERT, based on intravenous injection of an active form of recombinant enzyme whose deficiency causes the disease) can be used for treatment of MPS I, ${ }^{4-6}$ and it appears that analogous therapy should be generally available relatively soon for two other MPS types. ${ }^{7,8}$ This therapy is effective in treatment of somatic symptoms of MPS I, MPS II and MPS VI; however, when heparan sulphate cannot be degraded, severe neurological problems may occur, which cannot be managed by ERT owing to inefficient delivery of proteins, including those used as drugs, to central nervous system, because of the bloodbrain barrier. This is the case in some MPS I patients (subtype MPS IH), most of MPS II and MPS VII patients and all MPS III patients (all subtypes, ie IIIA, IIIB, IIIC and IIID). ${ }^{2}$ Sanfilippo disease (MPS III) seems to be especially problematic as this condition is associated with severe learning difficulty and behavioural disturbance and only relatively mild somatic involvement. In most affected patients, the progressive nature of the disease leads to death in the second, or rarely third decade of life. ${ }^{2}$ As the disorder primarily affects the brain and nervous system, attempts to cure the disorder have not been possible and the best that can be offered is palliative or symptomatic care.

Apart from provision of the deficient enzyme, another possible strategy for treatment of lysosomal storage disorders (including MPS) is reduction of the substrate whose degradation is impaired. ${ }^{9}$ For such a substrate reduction therapy (SRT), an analogue of a monomer that is incorporated into a complex macromolecule is usually considered. It may be a competitor of the natural substrate for an enzyme synthesizing the macromolecule. However, in the process leading to synthesis of GAGs, the monomers are carbohydrates or their derivatives that are also involved in many other metabolic pathways. ${ }^{10}$ Therefore, a putative competitor that could block activity of one of enzymes taking part in GAG synthesis, would most probably interfere with many other metabolic pathways, by blocking other biochemical reactions, thus giving potentially serious side effects. Therefore, to avoid this problem we aimed to develop SRT based on regulation of expression of genes coding for specific GAG synthetases.

\section{Materials and methods Culture media and reagents}

Dulbecco's modified Eagle's medium (DMEM), minimum essential medium (MEM), fetal bovine serum (FBS), antibiotic antimycotic solution (AAS), Dulbecco's phosphatebuffered saline (PBS), L-glutamine, 0.25\% trypsin-ethylene diaminetetraacetic acid solution, dimethyl sulfoxide (DMSO) and Proteinase K were from Sigma. Genistein was synthesized at the Pharmaceutical Research Institute, Warsaw and kindly provided by Grzegorz Grynkiewicz (Pharmaceutical Institute, Warsaw). $\mathrm{Na}_{2}\left[{ }^{35} \mathrm{~S}_{3} \mathrm{O}_{4}\right.$ was purchased from Amersham. PicoGreen ${ }^{\circledR}$ ds DNA Quantitation Reagent was obtained from Molecular Probes. Blyscan ${ }^{\mathrm{TM}}$ (Sulfated Glycosaminoglycan Assay) was from Biocolor Ltd. Recombinant human $\alpha$-L-iduronidase (Aldurazyme ${ }^{\circledR}$, laronidase) was obtained from Genzyme.

\section{Cell lines and cultivation conditions}

Skin fibroblast lines were initiated from forearm skin biopsies obtained from healthy volunteers and MPS patients, diagnosed on the basis of standard biochemical and enzymatic assays for levels of urinary GAGs and activity of lysosomal hydrolases, respectively. Fibroblasts of MPS I, MPS II, MPS IIIA and MPS IIIB patients were used. The MPS I patient was found (on the basis of DNA sequencing) to be homozygous for the Q70X mutation, a commonly found mutation in this disease. Cells were routinely grown in DMEM supplemented with 10\% heatinactivated $\mathrm{FBS}$ and $1 \times \mathrm{AAS}$ at $37^{\circ} \mathrm{C}$ in a humidified atmosphere of $5 \%(\mathrm{v} / \mathrm{v}) \mathrm{CO}_{2}$.

\section{Estimation of effects of genistein on GAG synthesis} Genistein was dissolved in DMSO and added to indicated final concentrations to cell cultures grown in DMEM (final DMSO concentration was $0.05 \%) .{ }^{11}$ Cells were preincubated in $25 \mathrm{~cm}^{2}$ flasks for $72 \mathrm{~h}$ in DMEM supplemented with appropriate amounts of genistein or $0.05 \%$ DMSO (control cultures). Then, the cells were plated in 24-well plates and allowed to attach to the wells for $24 \mathrm{~h}$. GAG synthesis was monitored by measurement of incorporation of ${ }^{35} \mathrm{~S}$ into proteoglycans, as described previously. ${ }^{12}$ Briefly, cells were labeled with either 20 or $40 \mu \mathrm{Ci} / \mathrm{ml}$ of $\mathrm{Na}_{2}\left[{ }^{35} \mathrm{~S} \mathrm{O}_{4}\right.$ for 24 or $48 \mathrm{~h}$ in a growth medium lacking inorganic sulfate (MEM), supplemented with $1 \%$ FBS and $1 \times$ AAS with appropriate genistein concentrations sustained. Fibroblasts were washed twice with PBS and cultures were subjected to papain digestion $(0.03 \%$ papain in $0.1 \mathrm{M}$ sodium acetate, $\mathrm{pH}$ 7.0). ${ }^{13}$ Aliquots of papain digest were used for ${ }^{35} \mathrm{~S}$ incorporation measurements in a scintillation counter. In all experiments, unlabeled control samples were processed in parallel for the determination of cell numbers. At the end of each experiment, cells were trypsinized and quantitated using a Thoma counter. For DNA quantitation, fibroblasts were subjected to proteinase digestion, then diluted (12-175 times depending on the intensity of the 
response to PicoGreen dye) and analyzed according to the protocol provided by the manufacturer of PicoGreen ${ }^{\circledR}$ ds DNA Quantitation Reagent. GAGs synthesis was calculated per cell or per DNA amount.

\section{Measurement of GAG levels in cells}

Fibroblasts were plated at 24-well plates and grown in DMEM supplemented with $10 \%$ FBS and $1 \times$ AAS with indicated concentrations of genistein or $0.05 \%$ DMSO (control cultures). Samples of cultures were withdrawn at indicated times, cells were washed with PBS and trypsinized $(80 \mu \mathrm{l} /$ well). DMEM with $10 \%$ FBS and $1 \times$ AAS (400 $\mu \mathrm{l} /$ well) was used to inactivate trypsin and this solution was transferred to $1.5 \mathrm{ml}$ Eppendorf tubes and centrifuged at 2000 r.p.m. in a microcentrifuge for $2 \mathrm{~min}$. Following removal of supernatant, the cells were digested with proteinase $\mathrm{K}\left(50 \mu \mathrm{g} / \mathrm{ml}\right.$ in $100 \mathrm{mM} \mathrm{K}_{2} \mathrm{HPO}_{4} \mathrm{pH} 8.0$; $400 \mu \mathrm{l} /$ tube) at $56^{\circ} \mathrm{C}$ overnight, as described previously. ${ }^{14}$ Then, proteinase $\mathrm{K}$ was inactivated at $90^{\circ} \mathrm{C}$ for $10 \mathrm{~min}$. The prepared samples were stored at $-20^{\circ} \mathrm{C}$ until used for sulfated GAG quantification with Blyscan Assay, and DNA measurement with PicoGreen ${ }^{\circledR}$ Quantitation Reagent, according to the manufacturer's instructions . Levels of GAGs were expressed per DNA amount.

\section{Electron microscopic analysis}

Aclar rectangles $(0.5 \times 1.0 \mathrm{~cm})$ were put into some of the wells prepared for the GAG quantitation experiment, removed between $\mathrm{PBS}$ wash and trypsinization and placed in fresh plates with fresh PBS in order to serve for microscopic examination. Transmission electron microscopy studies were performed as described previously, ${ }^{15}$ using a Philips CM100 microscope.

\section{Results}

It was demonstrated previously that maximum synthesis of at least some GAGs, including heparan sulphate and dermatan sulphate, requires either follicle-stimulating hormone or epidermal growth factor (EGF). ${ }^{16,17}$ The EGF influences expression of certain genes by binding to its transmembrane receptor, which upon interaction with EGF becomes an active protein kinase, initiating a specific kinase cascade that finally results in regulation of activity of particular transcription factors. An independent research line led to discovery that tyrosine-specific protein kinase activity of the EGF receptor is inhibited by genistein $\left(4^{\prime}\right.$, 5, 7-trihydroxyisoflavone or 5, 7-dihydroxy-3-(4hydroxyphenyl)-4H-1-benzopyran-4-one). ${ }^{18,19}$ Thus, we assumed that genistein may inhibit synthesis of GAGs owing to impairment of expression of genes coding for one or more of enzymes involved in this process. Some data obtained by others in experiments on cancer cells could suggest that this might be the case $;^{20-22}$ however, various cell lines gave different results, perhaps due to severe genetic changes in these cells.

We have treated cultures of fibroblasts of either a healthy person or MPS patients with various amounts of genistein and estimated synthesis of GAGs by measurement of radioactive $\left[{ }^{35} \mathrm{~S}_{\mathrm{O}} \mathrm{O}_{4}^{-2}\right.$ uptake. Such a procedure was adequate as in mammalian cells, $\mathrm{SO}_{4}^{-2}$ is incorporated almost exclusively into GAGs. ${ }^{23}$ We found that genistein inhibited GAG synthesis significantly in both wild-type and MPS cells (Figure 1). The most effective inhibition was observed at concentrations of genistein about $10-30 \mu \mathrm{M}$, and further increase in concentration of this isoflavone did not cause more pronounced effects (Figure 1 and data not shown).

Knowing that genistein can impair GAG synthesis, we asked about effects of this isoflavone on accumulation of these compounds in cells. Thus, quantification of unlabeled GAGs with Blyscan Assay was performed (see Materials and methods for details). Fibroblasts of a healthy person and of patients suffering from various MPS types were cultured for 6 days in the absence of genistein or in the presence of this compound at concentration giving optimal inhibition of GAG synthesis. At indicated times, GAG levels were estimated in cell samples. As a positive

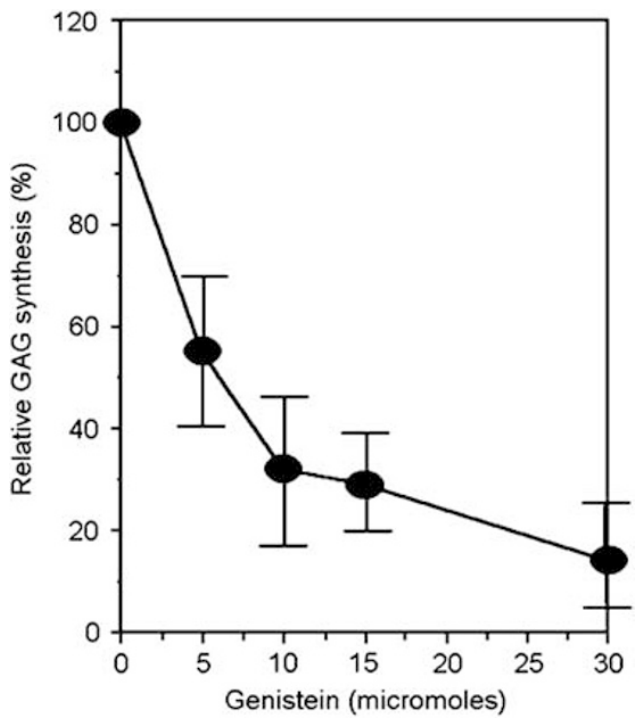

Figure 1 Effects of genistein (in micromoles per liter) on synthesis of GAGs in fibroblasts of the MPS I patient. Cells were cultured in the presence of $\mathrm{Na}_{2}\left[{ }^{35} \mathrm{~S}^{\mathrm{O}} \mathrm{O}_{4}\right.$ as described in Materials and methods for $48 \mathrm{~h}$, radioactivity of incorporated ${ }^{35} \mathrm{~S}$ was measured in a scintillation counter and calculated per DNA amount. $100 \%$ corresponds to $33.2 \mathrm{dpm} / \mathrm{ng}$ DNA and other presented values reflect this value. Similar results were obtained when cells were cultured for $24 \mathrm{~h}$ in the presence of $\mathrm{Na}_{2}\left[{ }^{35} \mathrm{~S}_{0} \mathrm{O}_{4}\right.$ and when the radioactivity was calculated per cell number (data not shown). Moreover, similar results were obtained when fibroblasts from either a healthy person or other MPS types (MPS II, MPS IIIA and MPS IIIB) were analysed (data not shown). Further increase in genistein concentration (up to $0.1 \mathrm{mM}$ ) did not result in more efficient inhibition of GAG synthesis than that observed at $30 \mu \mathrm{M}$ (data not shown). The results presented are average values from three measurements with bars indicating standard deviation. 

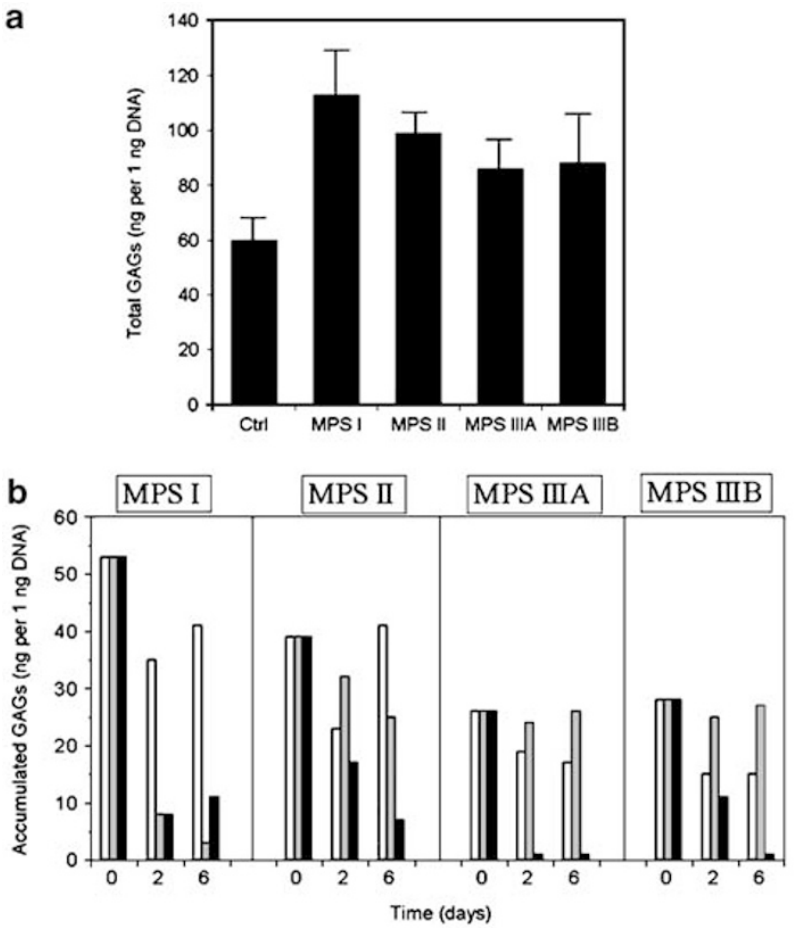

Figure 2 Effects of genistein on accumulation of GAGs in fibroblasts of MPS patients. (a) Levels of GAGs in untreated cultured fibroblasts of a healthy person and MPS I, MPS II, MPS IIIA and MPS IIIB patients. The results presented are average values from three measurements with bars indicating standard deviation. (b) Accumulation of GAGs in fibroblasts of various MPS patients in cultures either untreated (open columns) or treated with Aldurazyme (100 U/l; grey columns) or genistein ( $10 \mu \mathrm{M}$; black columns) for 2 or 6 days. Values obtained for untreated wild-type fibroblasts (see column Ctrl in panel a for time 0 ) were subtracted from the values measured for each sample, and such calculated values are presented (no significant effects of either genistein or Aldurazyme on GAG levels was observed in wildtype fibroblasts, ie at times 0,2 and 6 days all measured values were around $60 \mathrm{ng}$ GAG per $1 \mathrm{ng}$ DNA; thus, in the case of control experiments, all values in a putative subpanel $C$ trl in panel $b$ would be around 0 ). Average results from three measurements are shown; in each case s.d. was below $20 \%$.

control, we used MPS I cells treated with recombinant human $\alpha$-L-iduronidase (laronidase, Aldurazyme), an enzyme used in ERT for MPS I. In all cases (MPS I, MPS II, MPS IIIA and MPS IIIB), addition of genistein to cell cultures resulted in significant reduction of GAG storage (Figure 2). Interestingly, in MPS I fibroblasts, the effect of genistein after prolonged incubation (from 2 to 6 days) was comparable to that observed for Aldurazyme.

Various abnormal structures (onion skin structures, zebra bodies, flocculent inclusions and complex vacuoles with inclusions) are frequently found during electron microscopic analysis of cells of patients suffering from MPS. ${ }^{2}$ According to this, abundant abnormal structures were observed in untreated MPS I fibroblasts (grown in cell cultures) in electron microscopic analysis (Figure 3b). As expected, addition of Aldurazyme into the MPS I cell culture caused a significant decrease in size and number of such structures in cells (Figure 3c), which became more similar to fibroblasts of a healthy person (Figure 3a). However, similar normalization was also observed in MPS I cells treated with genistein (Figure $3 \mathrm{~d}$ ). The changes were both qualitative (Figure 3) and quantitative, as estimated by counting of abnormal structures in cells and calculating them per $10 \mu \mathrm{m}^{2}$ of cell cross-section (Table 1 ).

In all our cell culture experiments we were not able to observe any changes in cell integrity and proliferation in the presence of genistein (at concentrations up to $30 \mu \mathrm{M}$ ) relative to untreated cultures (data not shown). This applied to wild-type cells and all cell lines derived from MPS patients.

\section{Discussion}

As MPS, a group of genetic, metabolic diseases caused by defects in degradation of GAGs, are fatal disorders, for which no treatment is currently available or should be available soon, except type VI and non-neurodegenerative forms of types I and II, development of new potential therapeutic strategies appears to be of high importance. Treatment of neurodegenerative forms of MPS, which are predominant, is not possible now, even though ERT can be available, owing to the problem with crossing the bloodbrain barrier by enzymes. The use of small molecules, which could modulate GAG metabolism, might potentially overcome this difficulty. Moreover, efficiency of correction of various somatic tissues and organs of MPS patients during ERT may vary considerably, ${ }^{6}$ thus further improvement of GAG turnover in these patients is still desired.

Our studies demonstrated that treatment with genistein, which causes impairment of GAG synthesis, may be an effective method for reduction of GAG storage in cells of MPS patients, certainly MPS I, MPS II, MPS IIIA and MPS IIIB, and normalization of these cells. One might predict that inhibition of GAG synthesis can only halt further accumulation of these compounds in MPS cells rather than cause a decrease in their levels in cells. Contrary to such a prediction, we observed a clear reduction in GAG storage in affected cells. This may be caused by either degradation of accumulated GAGs by residual activity of the deficient enzyme, which could be the case if GAG synthesis rate was lower than the rate of their degradation, or dilution of GAGs in fibroblasts as cells divide, which would be the case if GAG synthesis was too slow to ensure doubling of GAG amount before each cell division, or both. Interestingly, reduction in GAG storage and normalization of cells were observed in fibroblasts of an MPS I patient who is homozygous for Q70X mutation, causing no detectable residual activity of $\alpha$-L-iduronidase - an enzyme deficient in MPS I. 

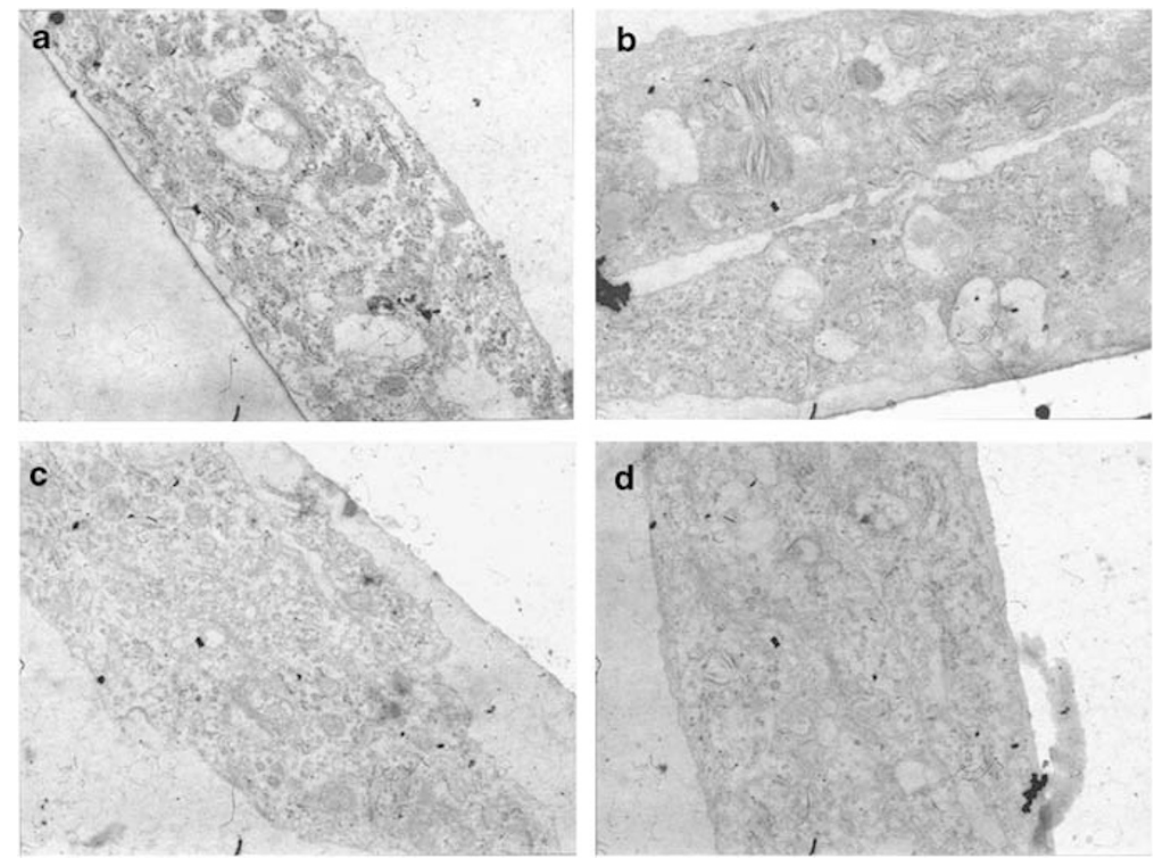

Figure 3 Electron microscopic analysis of untreated fibroblasts of a healthy person (a) and the MPS I patient (b), and MPS I fibroblasts from the same culture treated with Aldurazyme $(100 \mathrm{U} / \mathrm{l})(\mathrm{c})$ or genistein $(10 \mu \mathrm{M})(\mathrm{d})$ for 6 days.

Table 1 Quantitative analysis of electron microscopic studies on effects of Aldurazyme and genistein on accumulation of storage materials (visible under a microscope as various, but characteristic, abnormal structures) in cultured fibroblasts

\begin{tabular}{|c|c|c|c|c|}
\hline \multirow[t]{2}{*}{ Abnormal structures } & \multicolumn{4}{|c|}{ Average number per $10 \mu \mathrm{m}^{2}$ of cell cross-section } \\
\hline & Wild-type (untreated) & MPS I (untreated) & MPS I+Aldurazyme & MPS I+genistein \\
\hline Complex and large onion skin & 0.12 & 1.32 & 0.28 & 0.54 \\
\hline Flocculent inclusions & 0.16 & 1.78 & 0.21 & 0.18 \\
\hline Complex vacuoles (often with inclusions) & 0 & 0.49 & 0 & 0.05 \\
\hline Total & 0.36 & 4.61 & 0.92 & 1.13 \\
\hline
\end{tabular}

Cellular structures were analysed in fibroblasts from cultures (>100 cells in each case) exemplified in Figure 3.

Importantly, in both wild-type (control) cells and MPS fibroblasts, treatment with genistein did not cause reduction of GAG levels to the amount significantly lower than that measured in untreated wild-type cells, considered to be a normal level (Figure 2 and data not shown). This indicates that such a treatment, despite causing significant reduction in GAG synthesis rate, ensures maintenance of sufficient amounts of GAG, which is necessary for proper functions of cells and tissues. One may assume that this is due to a putative feedback regulation, which senses GAG levels and responds to changes in the rate of synthesis of these compounds, and directs for degradation only an excess of GAGs.

On the basis of results presented in this report, we propose to consider the use of genistein as a potential method for treatment of MPS. Results presented in this paper may serve as proof-of-principle of this novel therapeutic approach at a cellular level. Because of the suggested mechanism of action of genistein (an isoflavone), we propose to call this type of treatment 'gene expression-targeted isoflavone therapy' (GET IT). Although ERT may be potentially more efficient in treatment of at least some somatic tissues of MPS patients, ${ }^{6,24,25}$ an advantage of GET IT is that genistein is able to cross the blood-brain barrier. ${ }^{26}$ Therefore, this might be a chance for treatment of neurological symptoms of MPS, which is currently not possible. Although intrathecal administration of Aldurazyme was shown to reduce lysosomal storage in the brain and meninges of the canine model of MPS I, ${ }^{27}$ this technique may be problematic in the case of hyperactive children in which every anesthetic procedures are dangerous, like in MPS II and MPS III patients. ${ }^{2}$ It was 
demonstrated recently that using very high doses of recombinant human $\beta$-glucuronidase, it is possible to deliver small amounts of the enzyme to brains of MPS VII mice; ${ }^{28}$ however, it is not clear whether this partial overcoming of the blood-brain barrier might be sufficient to cause significant therapeutic effects in mice. Even if so, one might easily imagine various problems (both medical and economical) with provision of very high amounts of the enzyme to human patients suffering from MPS VII and other MPS types. GET IT, apart from being a potential method for treatment of neurological symptoms of MPS, would also be an option for any MPS patients who are unable or unwilling to receive ERT. In fact, one might also suppose that combination of GET IT with ERT (and/or another therapeutic procedure) could be an optimal method for treatment of MPS.

It is obvious that further in vitro and in vivo studies, including clinical trials, are necessary before GET IT can be considered a real treatment for MPS patients. A crucial issue that should be discussed is a possibility of potential side effects of such a treatment. As genistein is an inhibitor of protein kinase activity of the EGF receptor, ${ }^{18,19}$ which is involved in many signal transduction processes, one might be afraid that some essential regulatory pathways could be influenced. On the other hand, at concentrations studied in this work, genistein is not able to block the EGF receptor activity completely. In fact, although impairment of proliferation of cancer cells was observed at relatively high concentrations of genistein, ${ }^{11,22}$ we did not observe any significant changes in cell integrity and proliferation in wild-type and MPS fibroblasts treated with $10-30 \mu \mathrm{M}$ genistein. Thus, the effect of high concentrations of genistein on proliferation of cancer cells might be a partial explanation of various effects of this compound observed in different cancer cell lines reported previously, ${ }^{20-22}$ but serious side effects of moderate doses of genistein mediated by inhibition of EGF receptor kinase activity seem to be unlikely. Such a prediction is supported by results of studies, in which administration of genistein was demonstrated to be well tolerated and safe for animals and humans, even at doses several folds higher than those employed in our experiments. ${ }^{29-33}$

Other putative side effects of genistein could be caused by its phytoestrogenic activity. ${ }^{34}$ This might concern mainly children, owing to a potential influence on puberty and fertility. In fact, decreased fertility in males was reported as the only significant side effect in studies on the use of genistein or soy isoflavones as potential drugs and nutritional supplements for humans and animals. ${ }^{29-36}$ However, if genistein were effective in alleviation of MPS symptoms, the benefits for patients would be significantly more important than such a side effect. Although mutagenic or genotoxic activities of genistein have been reported in cell culture and animal studies, these effects were observed only at very high concentrations or doses of this isoflavone, ${ }^{37}$ thus, corresponding side effects during a potential treatment of MPS patients are unlikely.

\section{Acknowledgements}

We are grateful to Jerzy Bohdanowicz for his help and advice in electron microscopic analyses. This work was funded by the British Society for Mucopolyssacharide Diseases (project no. J4G/25/04), Daniels Sanfilippo Fund (Grant no. DSF-UG-01/2005) and Polish Ministry of Education and Science (project no. 2 P05A 103 26). The use of genistein in treatment of mucopolysaccharidoses is a subject of patent application (application no. P-377180).

\section{References}

1 Raman R, Sasisekharan V, Sasisekharan R: Structural insights into biological roles of protein-glycosaminoglycan interactions. Chem Biol 2005; 12: 267-277.

2 Neufeld EF, Muenzer J: The mucopolysaccharidoses; in Scriver CR, Beaudet AL, Sly WS, Valle D (eds):: The Metabolic and Molecular Bases of Inherited Disease. New York: McGraw-Hill Co, 2001, pp 3421-3452.

3 Węgrzyn G, Wẹgrzyn A, Tylki-Szymańska A: A general model for genetic regulation of turnover of glycosaminoglycans suggests a possible procedure for prediction of severity and clinical progress of mucopolysaccharidoses. Med Hypoth 2004; 62: 986-992.

4 Kakkis ED, Muenzer J, Tiller GE et al: Enzyme-replacement therapy in mucopolysaccharidosis I. New Engl J Med 2001; 344: $182-188$.

5 Wraith JE, Clarke LA, Beck M et al: Enzyme replacement therapy for mucopolysaccharidosis I: a randomized, double-blinded, placebo-controlled, multinational study of recombinant human $\alpha$-L-iduronidase (Laronidase). J Pediatr 2004; 144: 581-588.

6 Wraith JE: The first 5 years of clinical experience with laronidase enzyme replacement therapy for mucopolysaccharidosis I. Expert Opin Pharmacother 2005; 6: 489-506.

7 Muenzer J, Lamsa JC, Garcia A, Dacosta J, Garcia J, Treco DA: Enzyme replacement therapy in mucopolysaccharidosis type II (Hunter syndrome): a preliminary report. Acta Paediatr Suppl 2002; 91: 98-99.

8 Harmatz P, Whitley CB, Waber L et al: Enzyme replacement therapy in mucopolysaccharidosis VI (Maroteaux-Lamy syndrome). J Pediatr 2004; 144: 574-580.

9 Cox TM: Substrate reduction therapy for lysosomal storage diseases. Acta Pediatr Suppl 2005; 94: 69-75.

10 Sato T, Gotoh M, Kiyohara $\mathrm{K}$ et al: Differential roles of two $\mathrm{N}$-acetylgalactosaminyltransferases, CSGalNAcT-1, and a novel enzyme, CSGalNAcT-2. J Biol Chem 2003; 278: 3063-3071.

11 Brown A, Jolly P, Wai H: Genistein modulates neuroblastoma cell proliferation and differentiation through induction of apoptosis and regulation of tyrosine kinase activity and $\mathrm{N}$-myc expression. Carcinogenesis 1998; 19: 991-997.

12 Murata M, Bonassar LJ, Wright M, Mankin HJ, Towle CA: A role for the interleukin-1 receptor in the pathway linking static mechanical compression to decreased proteoglycan synthesis in surface articular cartilage. Arch Biochem Biophys 2003; 413: 229-235.

13 Bartold PM, Moule AJ, Li H, Rigby P: Isolation and characterization of the proteoglycans synthesized by adult human pulp fibroblasts in vitro. Int Endod J 1995; 28: 163-171.

14 Barbosa I, Garcia S, Barbier-Chassefiere V, Caruelle JP, Martelly I, Papy-Garcia D: Improved and simple micro assay for sulfated glycosaminoglycans quantification in biological extracts and its use in skin and muscle tissue studies. Glycobiology 2003; 13: 647-653.

15 Paradisi M, McClintock D, Boguslavsky RL, Pedicelli C, Worman HJ, Djabali K: Dermal fibroblasts in Hutchinson-Gilford progeria syndrome with the lamin A G608G mutation have dysmorphic nuclei and are hypersensitive to heat stress. BMC Cell Biol 2005; 6: 27. 
16 Pisano MM, Greene RM: Epidermal growth factor potentiates the induction of ornithine decarboxylase activity by prostaglandins in embryonic palate mesenchymal cells: effects on cell proliferation and glycosaminoglycan synthesis. Dev Biol 1987; 122: 419-431.

17 Tirone E, D'Alessandris C, Hascall VC, Siracusa G, Salustri A: Hyaluronan synthesis by mouse cumulus cells is regulated by interactions between folicle-stimulating hormone (or epidermal growth factor) and a soluble oocyte factor (or transforming growth factor $\beta_{1}$ ). J Biol Chem 1997; 272: 4787-4794.

18 Akiyama T, Ishida J, Nakagawa $\mathrm{S}$ et al: Genistein, a specific inhibitor of tyrosine-specific protein kinase. J Biol Chem 1987; 262: 5592-5595.

19 Kim H, Peterson TG, Barnes S: Mechanisms of action of the soy isoflavone genistein: emerging role for its effects via transforming growth factor beta signaling pathways. Am J Clin Nutr 1998; 68: $1418 \mathrm{~S}-1425 \mathrm{~S}$.

20 Tzanakakis GN, Hjerpe A, Karamanos NK: Proteoglycan synthesis induced by transforming and basic fibroblast growth factors in human malignant mesothelioma is mediated through specific receptors and the tyrosine kinase intracellular pathway. Biochimie 1997; 79: 323-332.

21 Mitropoulou TN, Tzanakakis GN, Nikitovic D, Tsatsakis A, Karamanos NK: In vitro effects of genistein on the synthesis and distribution of glycosaminoglycans/proteoglycans by estrogen receptor-positive and -negative human breast cancer epithelial cells. Anticancer Res 2002; 22: 2841-2846.

22 Nikitovic D, Tsatsakis AM, Karamanos NK, Tzanakakis GN: The effects of genistein on the synthesis and distribution of glycosaminoglycans/proteoglycans by two osteosarcoma cell lines depends on tyrosine kinase and the estrogen receptor density. Anticancer Res 2003; 23: 459-464.

23 Kato M, Takeda S, Ogawara S, Takayama S: Effect of levofloxacin on glycosaminoglycan and DNA synthesis of cultured rabbit chondrocytes at concentrations inducing cartilage lesions in vivo. Antimicrob Agents Chemother 1995; 39: 1979-1983.

24 Kloska A, Bohdanowicz J, Konopa G et al: Changes in hair morphology of mucopolysaccharidosis I patients treated with recombinant human $\alpha$-l-iduronidase (laronidase, Aldurazyme). Am J Med Genet 2005; 139A: 199-203.

25 Wegrzyn G, Kurlenda J, Liberek A et al: Atypical microbial infections of digestive tract may contribute to diarrhea in mucopolysaccharidosis patients: a MPS I case study. BMC Pediatr 2005; 5: 9.

26 Tsai TH: Concurrent measurement of unbound genistein in the blood, brain and bile of anesthetized rats using microdialysis and its pharmacokinetic application. J Chromatogr A 2005; 1073: 317-322.

27 Kakkis E, McEntee M, Vogler C et al: Intrathecal enzyme replacement therapy reduces lysosomal storage in the brain and meninges of the canine model of MPS I. Mol Genet Metab 2004; 83: $163-174$.

28 Vogler C, Levy B, Grubb JH et al: Overcoming the blood-brain barrier with high-dose enzyme replacement therapy in murine mucopolysaccharidosis VII. Proc Natl Acad Sci USA 2005; 102: $14777-14782$.

29 Bloedon LT, Jeffcoat AR, Lopaczynski W et al: Safety and pharmacokinetics of purified soy isoflavones: single-dose administration to postmenopausal women. Am J Clin Nutr 2002; 76: $1126-1137$.

30 Busby MG, Jeffcoat AR, Bloedon LT et al: Clinical characteristics and pharmacokinetics of purified soy isoflavones: single-dose administration to healthy men. Am J Clin Nutr 2002; 75: 126-136.

31 McClain RM, Wolz E, Davidovich A, Pfannkuch F, Bausch J: Subchronic and chronic safety studies with genistein in dogs. Food Chem Toxicol 2005; 43: 1461-1482.

32 Ullmann U, Metzner J, Frank T, Cohn W, Riegger C: Safety, tolerability, and pharmacokinetics of single ascending doses of synthetic genistein (Bonistein) in healthy volunteers. Adv Ther 2005; 22: 65-78.

33 Fischer L, Mahoney C, Jeffcoat AR et al: Clinical characteristics and pharmacokinetics of purified soy isoflavones: multiple-dose administration to men with prostate neoplasia. Nutr Cancer 2004; 48: $160-170$

34 Barnes S: Soy isoflavones - phytoestrogens and what else? J Nutr 2004; 134: 1225S-1228S.

35 Giampietro PG, Bruno G, Furcolo G et al: Soy protein formulas in children: no hormonal effects in long-term feeding. I Pediatr Endocrinol Metab 2004; 17: 191-196.

36 Chen A, Rogan WJ: Isoflavones in soy infant formula: a review of evidence for endocrine and other activity in infants. Annu Rev Nutr 2004; 24: 33-54.

37 McClain RM, Wolz E, Davidovich A, Bausch J: Genetic toxicity studies with genistein. Food Chem Toxicol 2006; 44: 42-55. 